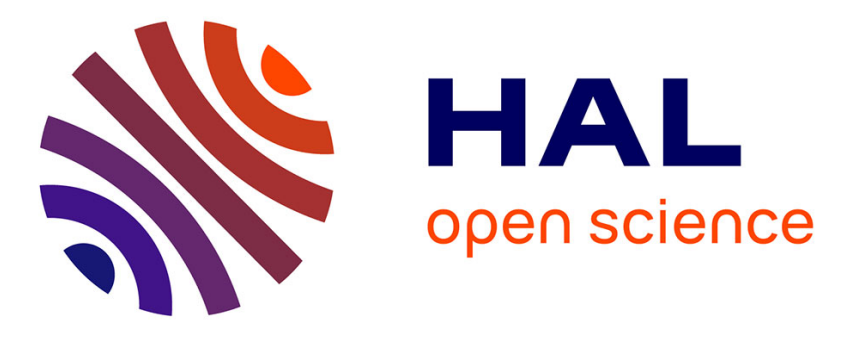

\title{
Modeling and actuators design of an unconventional airship
}

Mahmoud Khamlia, Selima Bennaceur, Naoufel Azouz, Sarra Samaali, Azgal Abichou, Jean Lerbet

\section{- To cite this version:}

Mahmoud Khamlia, Selima Bennaceur, Naoufel Azouz, Sarra Samaali, Azgal Abichou, et al.. Modeling and actuators design of an unconventional airship. ASME International Mechanical Engineering Congress and Exposition (IMECE 2015), Nov 2015, Houston, United States. 10.1115/IMECE201551475 . hal-01354277

\section{HAL Id: hal-01354277 https://hal.science/hal-01354277}

Submitted on 26 Dec 2019

HAL is a multi-disciplinary open access archive for the deposit and dissemination of scientific research documents, whether they are published or not. The documents may come from teaching and research institutions in France or abroad, or from public or private research centers.
L'archive ouverte pluridisciplinaire HAL, est destinée au dépôt et à la diffusion de documents scientifiques de niveau recherche, publiés ou non, émanant des établissements d'enseignement et de recherche français ou étrangers, des laboratoires publics ou privés. 


\section{Modeling and actuators design of an unconventional airship}

\author{
Mahmoud KHAMLIA \\ LIM, Ecole Polytechnique \\ La Marsa, TUNISIA
}

\author{
Sarra SAMAALI \\ LIM, Ecole Polytechnique \\ La Marsa, TUNISIA
}

\author{
Sélima BENNACEUR \\ LIM, Ecole Polytechnique \\ La Marsa, TUNISIA
}

\author{
Azgal ABICHOU \\ LIM, Ecole Polytechnique \\ La Marsa, TUNISIA
}

\author{
Naoufel AZOUZ \\ IBISC, University of Evry \\ Evry, FRANCE
}

\author{
Jean LERBET \\ IBISC, University of Evry \\ Evry, FRANCE
}

\section{ABSTRACT}

This paper presents a dynamic modeling of a quadrotor flying wing airship. This airship is a scale model of airships dedicated for freight transport. It is equipped with steerable thrusters that made over-actuated. A control strategy based on the linearization of the local equation and the use of backstepping control is applied to this model. We made a focus on the relations between the control vectors obtained from the control strategy and the response of the airship actuators.

Numerical results show the benefits of the proposed algorithm.

Keywords: unmanned aerial vehicle, dynamics model, overactuated system, controls-actuators relations.

\section{INTRODUCTION}

The interest for the modeling and control of airships increases significantly in the last years. Recent developments in lightweight materials, renewable energy technologies and embedded electronics have generated a renewed interest in an old concept. The complexity and capability of airships are expanding rapidly and the range of missions they designed to support is growing [1-2]. This may represent a revolution, especially in freight transport. However, in order for airships to reach this potential, significant technical issue must be overcome.

Among the different challenges faced, the optimization of the shapes and the actuators of big airships is a need that has become achievable through the advancement of aerodynamics and control theory. Usually, ellipsoidal shapes are used for airships [3-5]. However, and in order to optimize their performances, different original shapes are tested in the last years [6-9].

One main difference between traditional ellipsoidal shapes and unconventional ones is the fact that in the first case the theory is well established for over a century [10-11], and in second case everything remains to be done in the fields of modeling and control. Hence, there is an open area of research on how to make the dynamic and aerodynamic models precise. The tradeoffs are between the realistic sense of the model and the complexity to elaborate convenient algorithms of control, stabilization or navigation of these flying objects.

The airship studied here departs with the traditional shapes. The MC500 (see figure1) is a quadrotor flying wing, developed by the French network DIRISOFT. The MC500 is an experimental prototype for a set of great innovating airships. A precise dynamics model is needed for this kind of unmanned airships.

In this paper we present the dynamic model of the airship MC500 and the design of its actuators. The design of the propellers was made so that the airship can stabilize quickly and oppose a flurry of pre-detected wind. Each propeller has two degrees of freedom of rotation. The system is thus overactuated. A control strategy based on the linearization of the local equation and the use of backstepping control is applied to this model. We should remark that the backstepping technique is extensively used for flying objects [12-15].

The link between the control vectors from the control strategy and the response of the actuators is studied here. The system equations obtained is highly nonlinear and rectangular. The inversion of this system equations for the determination of the actuators reactions requires the introduction of some assumptions and the incorporation of additional constraints of optimization, taking into account the real physical constraints (kinematics and power) for obtaining feasible reactions of the actuators and minimizing the total energy supplied.

To evaluate the robustness of our method numerical tests are done. They concern the stabilization of the airship around an unloading area. Experimental tests will be done in the next months to validate our results. 


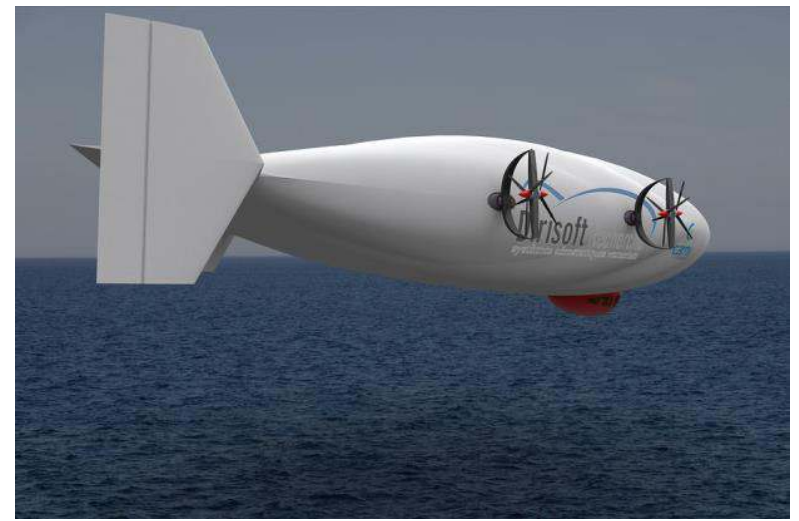

Figure 1. The airship MC500

\section{NOMENCLATURE}

$\eta_{1}=\left[x_{0}, y_{0}, z_{0}\right]^{T}$ : Vector position of the origin of the body-fixed airframe $R_{m}$ expressed in the fixed reference frame $R_{0}$,

$\eta_{2}=[\phi, \theta, \psi]^{T}:$ Vector orientation of the body-fixed airframe $R_{m}$ in regards to $R_{0}$ and given by the Euler angles,

$\eta=\left[\eta_{1}, \eta_{2}\right]^{T}:$ Vector attitude compared to $R_{0}$,

$\dot{\eta}$ : Velocity Vector compared to $R_{0}$ expressed in $R_{0}$,

$v=\left[v_{1}, v_{2}\right]^{T}$ Velocities vector expressed in $R_{0}$.

$v_{1}=[u, v, w]^{T}:$ Linear Velocity Vector,

$v_{2}=[p, q, r]^{T}:$ Angular Velocity Vector

$\mathrm{m}:$ the mass of the airship.

\section{DYNAMIC MODEL}

\section{I.1. Dynamics of the airship}

To describe the motion of the MC500, we used two reference frames. First an earth-fixed frame $R_{0}=\left(O, X_{0}, Y_{0}, Z_{0}\right)$, Then a local reference frame $R_{m}=\left(G, X_{m}, Y_{m}, Z_{m}\right)$ fixed at the center of gravity of the airship G. Its axes are selected as follows (figure 2):

$X_{m}$ is the longitudinal axis of the airship, $Y_{m}$ is the transverse axis, and $Z_{m}$ the normal axis directed downwards.

The orientation of the airship is defined through a parameterization in yaw, pitch and roll $(\psi, \theta, \phi)$.
Unlike heavier than air flying objects, in the modeling of an airship, it is essential to take into account the influence of the added masses. These latest are produced by the following phenomenon: When a big and light object moves in the air, the kinetic energy of the particles of air produces an effect equivalent to an important growing of the mass and inertia of the body. As the airship displays a very large volume, its added masses and inertias become significant.

There is abundant literature on this subject (see [16] for more details). Note in particular the work of Lamb [10]. He proves that the kinetic energy of the fluid surrounding the body can be expressed as a quadratic function of the six components of the translation and rotation velocity as follows:

$$
\mathrm{T}=\frac{1}{2} v^{\mathrm{T}} \underbrace{\left(\mathrm{M}_{\mathrm{b}}+\mathrm{M}_{\mathrm{a}}\right)}_{\mathrm{M}} v=\mathrm{T}_{\mathrm{b}}+\mathrm{T}_{\mathrm{a}}
$$

Where $\mathrm{M}_{\mathrm{b}}$ is the mass matrix of the body, $\mathrm{M}_{\mathrm{a}}$ is the added mass matrix due to the motion of the surrounding air. It is determined using a geometrical method. Calculation details of the matrix $\mathrm{M}_{\mathrm{a}}$ of the airship can be seen in [16].

The whole mass matrix $\mathrm{M}$ is assumed symmetric block-diagonal matrix.

$$
M=\left(\begin{array}{cc}
M_{T T} & 0 \\
0 & M_{R R}
\end{array}\right)
$$

For the computation of the whole dynamics model, we choose to use the Kirchoff's equation [17]:

$$
\begin{aligned}
& \frac{\mathrm{d}}{\mathrm{dt}}\left(\frac{\partial \mathrm{T}}{\partial \mathrm{v}_{1}}\right)+v_{2} \wedge \frac{\partial \mathrm{T}}{\partial \mathrm{v}_{1}}=\tau_{1} \\
& \frac{\mathrm{d}}{\mathrm{dt}}\left(\frac{\partial \mathrm{T}}{\partial \mathrm{v}_{2}}\right)+v_{2} \wedge \frac{\partial \mathrm{T}}{\partial v_{2}}+v_{1} \wedge \frac{\partial \mathrm{T}}{\partial v_{1}}=\tau_{2}
\end{aligned}
$$

$\tau_{1}$ and $\tau_{2}$ are respectively the external forces and torques, including the rotors effects, the weight (m.g), the buoyancy $B_{u}$, and the aerodynamic lift $\left(\mathrm{F}_{\mathrm{L}}\right)$ and $\operatorname{drag}\left(\mathrm{F}_{\mathrm{D}}\right)$.

The dynamical system of the airship becomes [5]: 


$$
\left(\begin{array}{cc}
M_{T T} & 0 \\
0 & M_{R R}
\end{array}\right)\left(\begin{array}{l}
\dot{v}_{1} \\
\dot{v}_{2}
\end{array}\right)=\left(\begin{array}{c}
\tau_{1}-v_{2} \wedge\left(M_{T T} v_{1}\right) \\
\tau_{2}-v_{2} \wedge\left(M_{R R} v_{2}\right)-v_{1} \wedge\left(M_{T T} v_{1}\right)
\end{array}\right)
$$

\section{I.2. Description of the rotors}

The airships covered have a huge volume and are therefore very sensitive to wind. It is then necessary to equip them with rotors that can be oriented in different directions to avoid large gaps especially in the phases of loading and unloading. The design of the four propellers was made so that the airship can stabilize quickly and oppose a flurry of pre-detected wind. The MC500 has four electric engines driving rotors. Each rotor has two parallel contra-rotating propellers to avoid any aerodynamic torque. (Figure2). The rotor can swivel in two directions. A rotation of angle $\beta_{\mathrm{i}}$ around the $Y_{m}$ axis $\left(-180^{\circ} \leq \beta_{\mathrm{i}} \leq 180^{\circ}\right)$, and a rotation of angle $\gamma_{i}$ around an axis $Z_{i R}$ normal to $Y_{m}$ and initially coinciding with the $Z_{m}$ axis $\left(-30^{\circ} \leq \gamma_{i} \leq 30^{\circ}\right)$. A fictive axis $X_{i R}$ completes the rotor frame.

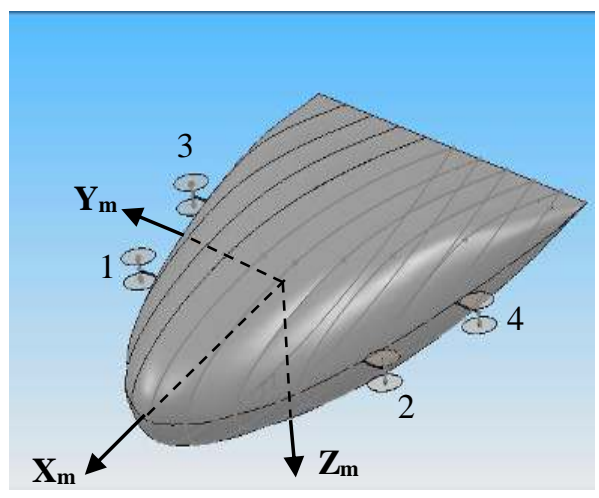

Figure 2. Position of the rotors

Let us denote $\mathrm{P}_{\mathrm{i}}$ the position of the rotor $\mathrm{i}$,. We can then define a rotation matrix $\mathrm{J}^{\mathrm{i}}$ between the frame $\left(\mathrm{P}_{\mathrm{i}}, \mathrm{X}_{\mathrm{iR}}, \mathrm{Y}, \mathrm{Z}_{\mathrm{iR}}\right)$ and the local frame $\mathrm{R}_{\mathrm{m}}$ such as:

$\mathbf{J}^{\mathrm{i}}=\left(\begin{array}{ccc}\mathrm{c} \gamma_{\mathrm{i}} \mathrm{c} \beta_{\mathrm{i}} & -\mathrm{s} \gamma_{\mathrm{i}} \mathrm{c} \beta_{\mathrm{i}} & \mathrm{s} \beta_{\mathrm{i}} \\ \mathrm{s} \gamma_{\mathrm{i}} & \mathrm{c} \gamma_{\mathrm{i}} & 0 \\ -\mathrm{c} \gamma_{\mathrm{i}} \mathrm{s} \beta_{\mathrm{i}} & \mathrm{s} \gamma_{\mathrm{i}} \mathrm{s} \beta_{\mathrm{i}} & \mathrm{c} \beta_{\mathrm{i}}\end{array}\right)$

We denote by: $\mathrm{c} \theta=\cos \theta ; \mathrm{s} \phi=\sin \phi ; \mathrm{t} \psi=\tan \psi$
The positions $\mathrm{Pi}_{\mathrm{i}}$ of the rotors in the local reference frame are as follows:

$$
\mathrm{P}_{1}=\left(\begin{array}{c}
\mathrm{a} \\
\mathrm{b}_{1} \\
\mathrm{c}
\end{array}\right) \quad ; \quad \mathrm{P}_{2}=\left(\begin{array}{c}
\mathrm{a} \\
-\mathrm{b}_{1} \\
\mathrm{c}
\end{array}\right) \quad ; \quad \mathrm{P}_{3}=\left(\begin{array}{c}
-\mathrm{a} \\
\mathrm{b}_{3} \\
\mathrm{c}
\end{array}\right) \quad ; \quad \mathrm{P}_{4}=\left(\begin{array}{c}
\mathrm{a} \\
-\mathrm{b}_{3} \\
\mathrm{c}
\end{array}\right)
$$

The values of $a, b_{1}, b_{2} a n d ~ c$ are given at the end of the paper.

If we suppose that the intensity of the thrust force of the rotor i is $\left\|F_{i}\right\|$, this force could be introduced in the second member of the dynamic equation as:

$$
\mathbf{F}_{\mathbf{i}}=\mathbf{J}^{\mathrm{i}}\left\|\mathrm{F}_{\mathrm{i}}\right\| \cdot \mathrm{e}_{\mathrm{X}_{\mathrm{m}}}
$$

Where $e_{X_{m}}$ is an unitary vector along the $X_{m}$ axis.

The torque produced by this rotor in the center of inertia $G$ is $\mathbf{F}_{\mathbf{i}} \wedge \mathbf{P}_{\mathbf{i}} \mathbf{G}$

\section{I.3. Weight and buoyancy}

An important characteristic of the airships is the buoyancy $\mathrm{B}_{\mathrm{u}}$. This force represents a natural static lift, corresponding roughly to $1 \mathrm{Kg}$ for each $\mathrm{m}^{3}$ of helium involved in the careen. We suppose here that this force is applied in the center of buoyancy $\mathrm{B}$ different from the center of inertia $\mathrm{G}$.

$$
\mathrm{B}_{\mathrm{u}}=\rho_{\mathrm{air}} \cdot \mathrm{V} \cdot \mathrm{g}
$$

where $\mathrm{V}$ is the volume of the careen, $\rho_{\text {air }}$ is the density of the air, and $g$ the gravity.

Let us note $\mathrm{F}_{\mathrm{WB}}$ and $\mathrm{M}_{\mathrm{WB}}$ the force and the moment due to the weight and buoyancy. We have:

$$
\begin{aligned}
& \mathbf{F}_{\mathbf{W B}}=.\left(\mathrm{mg}-\mathrm{B}_{\mathrm{u}}\right) \cdot \mathbf{J}_{1}^{\mathrm{T}} \mathbf{e z} \\
& \mathbf{M}_{\mathbf{W B}}=\mathrm{B}_{\mathrm{u}} \cdot\left(\mathrm{J}_{1}^{\mathrm{T}} \cdot \mathbf{e} \mathbf{Z} \wedge \mathbf{B G}\right)
\end{aligned}
$$

Note that such as other flying objects, the airships are subjected to aerodynamic forces. The resultant of these forces could be decomposed into two component forces, one parallel to the direction of the relative wind and opposite to the motion, called Drag, and the other perpendicular to the relative wind, called Lift. The MC500 is designed with an original shape oriented to a best optimization of the ratio lift upon drag forces.

However, and as first study, we try to evaluate the behavior of the airship in the case of hovering, which is the most critical 
situation. In that case, the effect of these forces could be neglected.

The global dynamic system could be expressed in a compact form as follows:

$$
\mathrm{M} \cdot \dot{v}=\tau+\mathbf{Q}_{\mathbf{G}}
$$

With :

$\tau=\left(\begin{array}{l}\tau_{1} \\ \tau_{2}\end{array}\right)$ the acting forces and torques.

and $\mathrm{Q}_{\mathrm{G}}$ the gyroscopic forces and torques.

Let us note $\mathrm{M}_{\mathrm{ij}}$ the terms of the whole mass matrix $\mathrm{M}$.

It should be mentioned that the coupling terms of the mass matrix of this airship $M_{45}$ and $M_{56}$ are null.

A classic transformation can express $\dot{\eta}$ in terms of $v$ [17].

This leads to the developed dynamics model:

$$
\left\{\begin{array}{l}
\dot{x}=c_{\psi} c_{\theta} u+\left(-s_{\psi} c_{\phi}+c_{\psi} s_{\phi} s_{\theta}\right) v+\left(s_{\psi} s_{\phi}+c_{\psi} c_{\phi} s_{\theta}\right) w \\
\dot{y}=s_{\psi} c_{\theta} u+\left(c_{\psi} c_{\phi}+s_{\psi} s_{\phi} s_{\theta}\right) v+\left(-c_{\psi} s_{\phi}+s_{\psi} c_{\phi} s_{\theta}\right) w \\
\dot{z}=-s_{\theta} u+s_{\phi} c_{\theta} v+c_{\phi} c_{\theta} w \\
\dot{\phi}=p+s_{\phi} t_{\theta} q+c_{\phi} t_{\theta} r \\
\dot{\theta}=c_{\phi} q-s_{\phi} r \\
\dot{\psi}=\frac{s_{\phi}}{c_{\theta}} q+\frac{c_{\phi}}{c_{\theta}} r \\
M_{11} \dot{u}=\alpha_{1}+Q_{1} \\
M_{22} \dot{v}=\alpha_{2}+Q_{2} \\
M_{33} \dot{w}=\alpha_{3}+Q_{3} \\
\left(M_{46}^{2}-M_{66} M_{44}\right) \dot{p}=M_{46} \alpha_{6}+M_{46} Q_{6}-M_{66} \alpha_{4}-M_{66} Q_{4} \\
M_{55} \dot{q}=\alpha_{5}+Q_{5} \\
\left(M_{46}^{2}-M_{66} M_{44}\right) \dot{r}=M_{46} \alpha_{4}-M_{44} \alpha_{6}+M_{46} Q_{4}-M_{44} Q_{6}
\end{array}\right.
$$

Such as:

$$
\left(\begin{array}{c}
\alpha_{1}=\sum_{k=1}^{4}\left\|F_{i}\right\| c_{\gamma_{i}} c_{\beta_{i}}-\left(m g-B_{u}\right) \cdot s_{\theta} \\
\alpha_{2}=\sum_{k=1}^{4}\left\|F_{i}\right\| s_{\gamma_{i}}-\left(m g-B_{u}\right) \cdot s_{\phi} \cdot c_{\theta} \\
\alpha_{3}=\sum_{k=1}^{4}\left\|F_{i}\right\| c_{\gamma_{i}} s_{\beta_{i}}-\left(m g-B_{u}\right) \cdot c_{\phi} c_{\theta}
\end{array}\right)
$$

$$
\left(\begin{array}{c}
\alpha_{4}=c \sum_{k=1}^{4}\left\|F_{i}\right\| s_{\gamma_{i}}+b_{1}\left(\left\|F_{1}\right\| c_{\gamma_{1}} s_{\beta_{1}}-\left\|F_{2}\right\| c_{\gamma_{2}} s_{\beta_{2}}\right)+ \\
b_{3}\left(\left\|F_{3}\right\| c_{\gamma_{3}} s_{\beta_{3}}-\left\|F_{4}\right\| c_{\gamma_{4}} s_{\beta_{4}}\right)+B_{u} z_{B} s_{\phi} c_{\theta} \\
\alpha_{5}=-c \sum_{k=1}^{4}\left\|F_{i}\right\| c_{\gamma_{i}} c_{\beta_{i}}+a\left(\left\|F_{4}\right\| c_{\gamma_{4}} s_{\beta_{4}}+\left\|F_{3}\right\| c_{\gamma_{3}} s_{\beta_{3}}-\left\|F_{1}\right\| c_{\gamma_{1}} s_{\beta_{1}}-\right. \\
\left.\left\|F_{2}\right\| c_{\gamma_{2}} s_{\beta_{2}}\right)+B_{u} z_{B} s_{\theta} \\
\alpha_{6}=b_{1}\left(\left\|F_{1}\right\| c_{\gamma_{1}} c_{\beta_{1}}-\left\|F_{2}\right\| c_{\gamma_{2}} c_{\beta_{2}}\right)+b_{3}\left(\left\|F_{3}\right\| c_{\gamma_{3}} c_{\beta_{3}}-\left\|F_{4}\right\| c_{\gamma_{4}} c_{\beta_{4}}\right)+ \\
\quad a\left(\left\|F_{4}\right\| s_{\gamma_{4}}+\left\|F_{3}\right\| s_{\gamma_{3}}-\left\|F_{1}\right\| s_{\gamma_{1}}-\left\|F_{2}\right\| s_{\gamma_{2}}\right)
\end{array}\right.
$$

and:

$$
\left(\begin{array}{c}
Q_{1} \\
Q_{2} \\
Q_{3} \\
Q_{4} \\
Q_{5} \\
Q_{6}
\end{array}\right)=\left(\begin{array}{c}
M_{22} v r-M_{33} q w \\
M_{33} p w-M_{11} u r \\
M_{11} u q-M_{22} v p \\
-M_{46} p q+\left(M_{55}-M_{66}\right) q r \\
M_{46} p^{2}+\left(M_{66}-M_{44}\right) p r+M_{46} r^{2} \\
\left(M_{44}-M_{55}\right) p q-M_{46} q r
\end{array}\right)
$$

We should denote $X=[x, y, z, \theta, \phi, \psi, u, v, w, p, q, r]^{t}$ : the state of the system, $U=\left[\alpha_{1}, \ldots, \alpha_{6}\right]^{t}:$ the control vector.

\section{Strategy OF CONTROL}

Our objective is to stabilize the airship to the vicinity of a target state $X_{d}=\left[x_{d}, y_{d}, z_{d}, \phi_{d}, \theta_{d}, \psi_{d}\right]$. The linearizedtangent method is used to achieve this goal. The linearizedtangent system error associated with the system is given by: 


$$
\left\{\begin{array}{l}
\dot{\xi}_{1}=u \\
\dot{\xi}_{2}=v \\
\dot{\xi}_{3}=w \\
\dot{\xi}_{4}=p \\
\dot{\xi}_{5}=q \\
\dot{\xi}_{6}=r \\
M_{11} \dot{u}=\alpha_{1} \\
M_{22} \dot{v}=\alpha_{2} \\
M_{33} \dot{w}=\alpha_{3} \\
\left(M_{46}^{2}-M_{66} M_{44}\right) \dot{p}=M_{46} \alpha_{6}-M_{66} \alpha_{4} \\
M_{55} \dot{q}=\alpha_{5} \\
\left(M_{46}^{2}-M_{66} M_{44}\right) \dot{r}=M_{46} \alpha_{4}-M_{44} \alpha_{6}
\end{array}\right.
$$

Knowing that: $\xi_{1}=x-x_{d}, \quad \xi_{2}=y-y_{d}, \quad \xi_{3}=z-z_{d}$, $\xi_{4}=\phi-\phi_{d}, \quad \xi_{5}=\theta-\theta_{d}, \quad \xi_{6}=\psi-\psi_{d} \cdot\left(\alpha_{j}\right)_{1 \leq i \leq 6}$ are the components of the "virtual" control vector.

Proposal : Consider the following control vector:

$$
\begin{aligned}
& \alpha_{1}=M_{11}\left(-k_{1} \dot{\xi}_{1}-k_{1}^{\prime} \xi_{1}\right) \\
& \alpha_{2}=M_{22}\left(-k_{2} \dot{\xi}_{2}-k_{2}^{\prime} \xi_{2}\right) \\
& \alpha_{3}=M_{33}\left(-k_{3} \dot{\xi}_{3}-k_{3}^{\prime} \xi_{3}\right)
\end{aligned}
$$

$$
\begin{aligned}
\alpha_{4}= & \frac{M_{44}}{\left(M_{46}^{2}-M_{66} M_{44}\right)^{2}}\left(-k_{4} \dot{\xi}_{4}-k_{4}^{\prime} \xi_{4}\right)+ \\
& \frac{M_{46}}{\left(M_{46}^{2}-M_{66} M_{44}\right)^{2}}\left(-k_{6} \dot{\xi}_{6}-k_{6}^{\prime} \xi_{6}\right)
\end{aligned}
$$

$$
\begin{aligned}
\alpha_{5}= & M_{55}\left(-k_{5} \dot{\xi}_{5}-k_{5}^{\prime} \xi_{5}\right) \\
\alpha_{6}= & \frac{M_{66}}{\left(M_{46}^{2}-M_{66} M_{44}\right)^{2}}\left(-k_{6} \dot{\xi}_{6}-k_{6}^{\prime} \xi_{6}\right)+ \\
& \frac{M_{46}}{\left(M_{46}^{2}-M_{66} M_{44}^{2}\right.}\left(-k_{4} \dot{\xi}_{4}-k_{4}^{\prime} \xi_{4}\right)
\end{aligned}
$$

with a good choice of $\left(k_{i}\right)_{1 \leq i \leq 6}$ and $\left(k_{i}^{\prime}\right)_{1 \leq i \leq 6}$, the airship MC500 is asymptotically stable in the neighborhood of the point $\left(x_{d} ; y_{d} ; z_{d} ; \phi_{d} ; \theta_{d} ; \psi_{d}\right)$.

\section{Proof :}

The system (4) is controllable. This result is proved by the Kalman controllability criterion. The $\left(\alpha_{j}\right)_{1 \leq j \leq 6}$ defined above ensure the stability of two subsystems:

$$
\begin{aligned}
& \left\{\begin{array}{l}
\dot{\xi}_{1}=u \\
\dot{\xi}_{2}=v \\
\dot{\xi}_{3}=w \\
\dot{\xi}_{5}=q \\
\dot{u}=\frac{\alpha_{1}}{M_{11}} \\
\dot{v}=\frac{\alpha_{2}}{M_{22}} \\
\dot{w}=\frac{\alpha_{3}}{M_{33}} \\
\dot{q}=\frac{\alpha_{3}}{M_{55}}
\end{array}\right. \\
& \left\{\begin{array}{l}
\dot{\xi}=p_{4} \\
\dot{\xi}=\frac{M_{46} \alpha_{6}-M_{66} \alpha_{4}}{\left(M_{46}^{2}-M_{66} M_{44}\right)}=c_{1} \alpha_{6}-c_{2} \alpha_{4} \\
\dot{r}=\frac{M_{46} \alpha_{4}-M_{44} \alpha_{6}}{\left(M_{46}^{2}-M_{66} M_{44}\right)}=c_{1} \alpha_{4}-c_{3} \alpha_{6}
\end{array}\right.
\end{aligned}
$$

We derived with respect to time the first four equations of the system (16), we obtain:

$$
\left\{\begin{array}{l}
\ddot{\xi}_{1}=\frac{\alpha_{1}}{M_{11}}=v_{1} \\
\ddot{\xi}_{2}=\frac{\alpha_{2}}{M_{22}}=v_{2} \\
\ddot{\xi}_{3}=\frac{\alpha_{3}}{M_{33}}=v_{3} \\
\ddot{\xi}_{5}=\frac{\alpha_{5}}{M_{55}}=v_{5}
\end{array}\right.
$$

We choose as an expression of $v_{i}$ :

$$
v_{i}=-k_{i} \dot{\xi}_{i}-k_{i}^{\prime} \xi_{i} \quad \forall i \in\{1,2,3,5\}
$$


With a good choice of the gains $k_{i}$ and $k_{i}^{\prime}$ we obtain the exponential stability in the vicinity of zero. Indeed, for this choice of control we have:

$\ddot{\xi}_{i}=-k_{i} \dot{\xi}_{i}-k_{i}^{\prime} \xi_{i} \quad \forall i \in\{1,2,3,5\}$.

It is a second order differential equation, that has as solution $C_{1} e^{r_{1} t}+C_{2} e^{r_{2} t}$.

Where $\mathrm{C}_{1}$ and $\mathrm{C}_{2}$ are constants and $\mathrm{r}_{1}, \mathrm{r}_{2}$ are the solutions of the characteristic equation: $r^{2}+k_{i} r+k_{i}^{\prime}=0$

for $k_{i}>2 \sqrt{k_{i}^{\prime}}$. As a result $\left(\xi_{i}\right)_{i} \in 1,2,3,5$ tends to zero when the time $t$ tends to $+\infty$.

To stabilize the system (17) we apply the backstepping technique. Using the following change of variables:

$\left\{\begin{array}{l}p_{1}=c_{3} p+c_{1} r \\ r_{1}=c_{1} p+c_{2} r\end{array}\right.$

We obtain the following equivalent system :

$$
\left\{\begin{array}{l}
\dot{\xi}_{4}=\frac{c_{2}}{-c_{1}^{2}+c_{3} c_{2}} p_{1}-\frac{c_{1}}{c_{1}^{2}-c_{3} c_{2}} r_{1}=A_{1} p_{1}-A_{2} r_{1} \\
\dot{\xi}_{6}=\frac{-c_{1}}{-c_{1}^{2}+c_{3} c_{2}} p_{1}+\frac{c_{3}}{-c_{1}^{2}+c_{3} c_{2}} r_{1}=-A_{2} p_{1}+A_{3} r_{1} \\
\dot{p}_{1}=\left(c_{1}^{2}-c_{3} c_{2}\right) \alpha_{4}=\alpha_{4}^{\prime} \\
\dot{r}_{1}=\left(c_{1}^{2}-c_{3} c_{2}\right) \alpha_{6}=\alpha_{6}^{\prime}
\end{array}\right.
$$

By applying the backstepping technique, one obtains the reduced system below which is obtained by taking $\alpha_{1}^{\prime \prime}$ and $\alpha_{2}^{\prime \prime}$ as "virtual" controls:

$\left\{\begin{array}{l}\dot{\xi}_{4}=A_{1} \alpha_{1}{ }^{\prime \prime}-A_{2} \alpha_{2}{ }^{\prime \prime} \\ \dot{\xi}_{6}=-A_{2} \alpha_{1}{ }^{\prime}+A_{3} \alpha_{2}{ }^{\prime \prime}\end{array}\right.$

with $\alpha_{4}{ }^{\prime}=-k_{4}\left(\xi_{4}-\alpha_{1}{ }^{\prime}\right), \alpha_{6}{ }^{\prime}=-k_{6}\left(\xi_{6}-\alpha_{2}{ }^{\prime}\right)$

We can apply the following change of variables: $\xi_{41}=A_{3} \xi_{4}+A_{2} \xi_{6}, \xi_{61}=A_{2} \xi_{4}+A_{1} \xi_{6}$
This leads to the equivalent system below :

$$
\left\{\begin{array}{l}
\dot{\xi}_{41}=\left(A_{3} A_{1}-A_{2}^{2}\right) \alpha_{1}^{\prime \prime} \\
\dot{\xi}_{61}=\left(A_{3} A_{1}-A_{1}^{2}\right) \alpha_{2}^{\prime \prime}
\end{array}\right.
$$

Finally, there was an equivalence between the asymptotic stabilization of the system (21) and that of (17). Therefore we will restrict the study to stabilize asymptotically close to zero the system (21). We choose as an expression of $\alpha_{1}^{\prime \prime}$ et $\alpha_{2}^{\prime \prime}$ :

$\alpha_{1}^{\prime \prime}=-k_{4}^{\prime} \xi_{41}$ et $\alpha_{2}^{\prime \prime}=-k_{6}^{\prime} \xi_{61}$

$k_{4}^{\prime}$ et $k_{6}^{\prime}$ are positive.

This choice guarantees asymptotic stabilization of the system (21) in the vicinity of zero. This result is proved by the Lyapunov theorem [18].

Just take the following Lyapunov function:

$V=\frac{1}{2} \xi_{i 1}^{2}, i \in\{4,6\}$,

and it will be noted that this function is positive definite and its derivative is defined negative.

\section{COMPUTATION OF THE ACTUATORS RESPONSE}

Let $u=\left[\alpha_{1}, \ldots, \alpha_{6}\right]^{t}$ be a given control vector that ensures the stabilization or path planning of the airship. To control the airship, we have to compute the forces generated by the rotors $F_{i}$ as well as their orientation angles $\beta \mathrm{i}$ and $\gamma \mathrm{i}$ and according to the commands $\alpha_{\mathrm{j}}$.

The inverse problem is highly nonlinear. The strategy to solve the connection problem is as follows:

We start by defining the force vector $F_{i}$ of the rotors $1 \leq i \leq 4$ given in (6):

$F_{i}=\left(\begin{array}{c}\left\|F_{i}\right\| c_{\gamma_{i}} c_{\beta_{i}} \\ \left\|F_{i}\right\| s_{\gamma_{i}} \\ -\left\|F_{i}\right\| c_{\gamma_{i}} s_{\beta_{i}}\end{array}\right)$ 
If we can determine the components of the forces vectors $F_{i}$, we can solve the connection problem considered.

Indeed, we note: $f_{i}=\left\|F_{i}\right\| c_{\gamma_{i}} c_{\beta_{i}}$

$$
\begin{aligned}
& g_{i}=\left\|F_{i}\right\| s_{\gamma_{i}} \\
& h_{i}=\left\|F_{i}\right\| c_{\gamma_{i}} s_{\beta_{i}}
\end{aligned}
$$

Find the relationship between the actuators and the "virtual" controls is equivalent to determine $f_{i}, g_{i}$ and $h_{i}$ in terms of $\alpha_{j}$

The nonlinear system which describes the relationship between the actuators and the controls found is given by the equation (12-b).

Using the expressions (23-25) we obtain the following rectangular linear system:

$$
\left\{\begin{array}{l}
\sum_{k=1}^{4} f_{i}=\alpha_{1}+\left(m g-B_{u}\right) \cdot s_{\theta} \\
\sum_{k=1}^{4} g_{i}=\alpha_{2}+\left(m g-B_{u}\right) \cdot s_{\phi} \cdot c_{\theta} \\
\sum_{k=1}^{4} h_{i}=\alpha_{3}+\left(m g-B_{u}\right) \cdot c_{\phi} \cdot c_{\theta} \\
c \sum_{k=1}^{4} g_{i}+b_{1}\left(h_{1}-h_{2}\right)+b_{3}\left(h_{3}-h_{4}\right)=\alpha_{4}-B_{u} z_{B} s_{\phi} c_{\theta} \\
-c \sum_{k=1}^{4} f_{i}+a\left(h_{3}+h_{4}-h_{1}-h_{2}\right)=\alpha_{5}-B_{u} z_{B} s_{\theta} \\
b_{1}\left(f_{1}-f_{2}\right)+b_{3}\left(f_{3}-f_{4}\right)+a\left(g_{4}+g_{3}-g_{1}-g_{2}\right)=\alpha_{6}
\end{array}\right.
$$

To determine the actuators $F_{i}, \gamma_{i}, \beta_{i}$ we should resolve the preceding rectangular system.

\section{Remark}

The philosophy of the choices proposed is based on energy considerations. Indeed for the sustenance of a flying object with four propeller engines, there are an infinite number of solutions. The most energy-efficient solution is one that balances the load on all four engines. That's why we imposed conditions to be closer to the load balancing configuration every time the operating conditions and stabilization permit.

The block diagram of the algorithm built is described by the following figure:

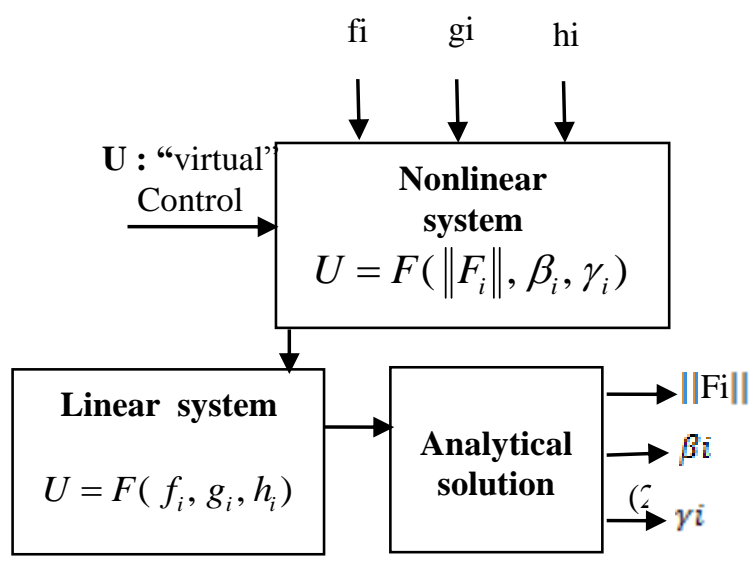

Figure3: Algorithm for computing the response of the actuators

\section{Simulation RESUlts}

In this section we present a numerical example that highlights the effectiveness of the algorithm developed in this paper.

As an illustration, we use the characteristics of the airship MC500 and featuring the following characteristics:

- Mass of the airship: $\mathrm{m}=600 \mathrm{Kg}$

- Acceleration of the gravity: $g=9.8 \mathrm{~m} . \mathrm{s}^{-2}$

- Buoyancy $\mathrm{Bu}_{\mathrm{u}}=5000 \mathrm{~N}$

- Vertical position of the center of gravity $\mathrm{ZG}=0.5 \mathrm{~m}$

- $\mathrm{a}=2.5 \mathrm{~m} ; \mathrm{b}_{1}=5.4 \mathrm{~m} ; \mathrm{b}_{3}=6.5 \mathrm{~m} ; \mathrm{c}=2 \mathrm{~m}$.

- Components of the total mass matrix $\mathrm{M}$ including the added masses effect:

$$
\begin{aligned}
& M_{11}=631 \mathrm{~kg} ; M_{22}=713 \mathrm{~kg} ; M_{33}=1322 \mathrm{~kg}(2 ; 8) \\
& M_{44}=9413 \mathrm{~kg} \cdot \mathrm{m}^{2} ; M_{55}=10456 \mathrm{~kg} \cdot \mathrm{m}^{2} ;
\end{aligned}
$$


$M_{66}=18700 \mathrm{~kg} \cdot \mathrm{m}^{2} ; M_{46}=160 \mathrm{~kg} \cdot \mathrm{m}^{2} ;$

The calculations were performed using the numerical code Matlab.

The test represents a destabilization of the airship over an unloading area. It relates to a change in orientation of the airship according to the three axes of yaw, roll, and pitch $\left(\psi_{0}=12^{\circ} ; \varphi_{0}=6^{\circ} ; \theta_{0}=18^{\circ}\right)$ as a result of a wind squall.
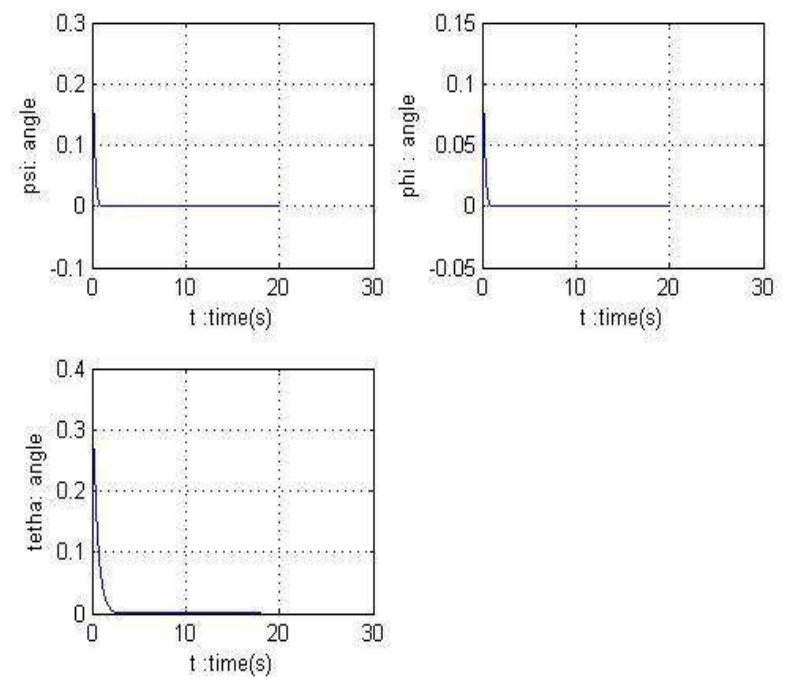

Figure 4: Orientation of the airship (Euler angles)

In Figure 4 we show the rapid decrease of the Euler angles to zero under the effect of the applied control law, in order to achieve the desired equilibrium position $(\psi=\varphi=\theta=0)$.

This effect is also seen on the response of the actuators. Figures 5-7 depict the situation considered. We see that the desired position is materialized by a stabilization of the actuator parameters around equilibrium values generating an energy minimum.
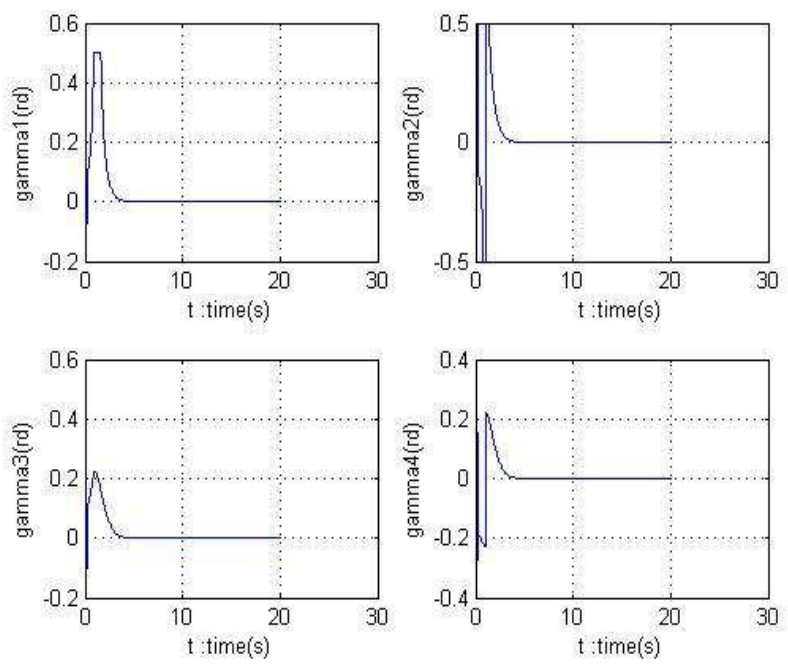

Figure 5: Azimuthal angles of the thrusters
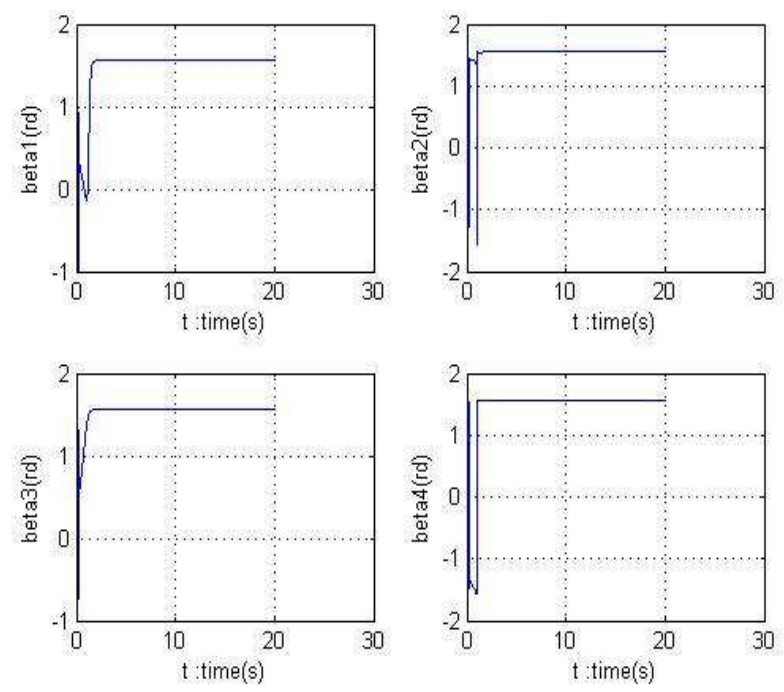

Figure 6: Transverse angles of the thrusters.

Although the choices imposed on actuators are associated to strong constraints linking these actuators, it nonetheless demonstrates the capability of the proposed algorithm to compute realistic values of the different parameters of the actuators as it optimizes the energy supplied. 

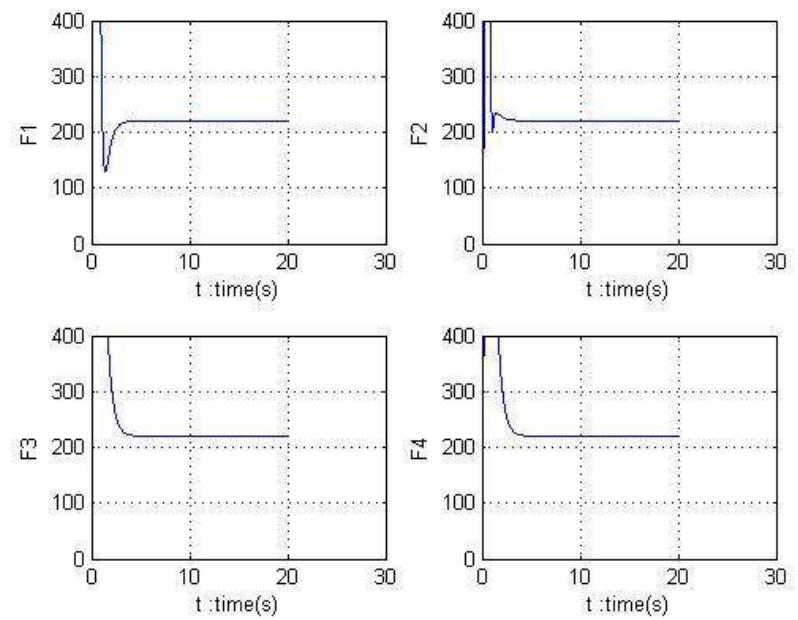

Figure 7: Forces developed by the rotors

Meanwhile, it can be seen in Figure 8 the calculation of the actuators thrust forces established by the inversion of a rectangular system through a standard pseudo-inverse method without using our algorithm. The results in that case are not realistic and therefore unusable.
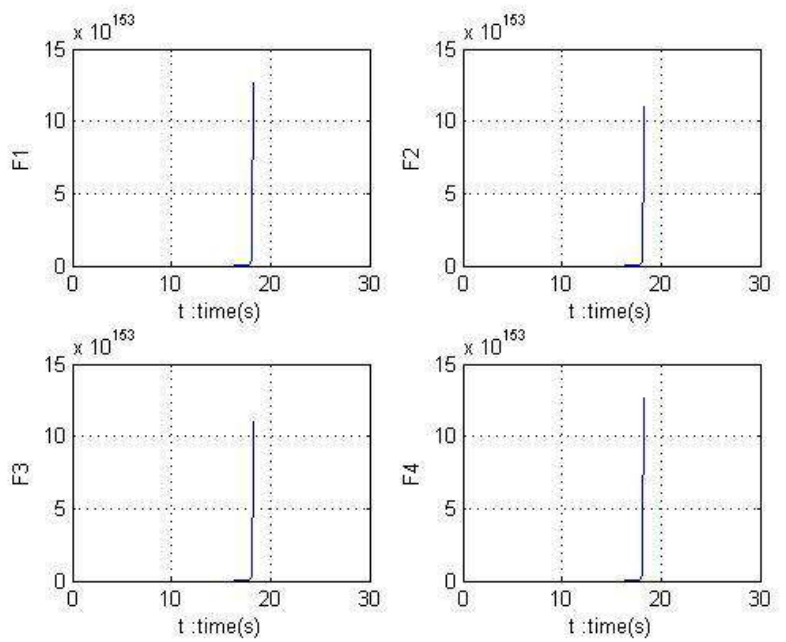

Figure 8: Forces developed by the rotors using pseudo-inverse method.

\section{CONCLUSION}

In this paper we have presented in the first part a dynamic modeling of an unconventional airship with steerable thrusters, designed for freight transport. A stabilization strategy is proposed in the second part. It is based on linearization and backstepping controller. This helped to develop an algorithm that has been applied to stabilize the airship over a loading area.
A design of the propellers is proposed. The airship is overactuated. By introducing some assumptions, and imposing certain choices, we have established analytical relations between the controls vector and the response of the actuators. Numerical results have validated the algorithm obtained and prove the relevance of our choices

\section{REFERENCES}

[1] L. Liao, I. Pasternak, (2009)." A review of airship structural research and developments. ’Prog. Aerosp. Eng. 45 (4-5), pp. 83-96.

[2] Y. Li, M. Nahon, I. SHARF, (2011).” Airship Dynamics modeling” Prog. Aerosp. Eng. 27, N³, pp.217-239.

[3] E. Hygounenc, II.Kyun Jung, Ph. Soueres, S.Lacroix (2004)"The Autonomous Blimp Project of LAAS-CNRS: Achievements in Flight Control and Terrain Mapping". Int. Jour. Robotics Research. Vol. 23, No. 4-5,pp. 473511.

[4] H.Jex,P. Gelhausen, (1985). "Control response measurements of the Skyship 500 Airship". Proc. of the 6thAIAA conf. Lighter than air technology, pp. 130-141, NY, USA.

[5] S. Bennaceur, N. Azouz(2012), "Contribution of the added masses in the dynamic modelling of flexible airships" Nonlinear Dynamics, Springer verlag (Germany), 67 (1), pp.215--226.

[6] P. Peddiraju , T. Liesk, M. Nahon (2009) "Dynamics modeling for an unmanned, unstable, fin-less airship".18th AIAA Lighter-Than-Air Systems Technology Conference. Seattle, USA.

[7] A.Ceruti,V. Voloshin,P. Marzocca (2014). "Heuristic Algorithms Applied to Multidisciplinary Design Optimization of Unconventional Airship". Journal of Aircraft. 51(6):1758-1772. DOI: 10.2514/1.C032439

[8] Y. Song, J. Mai, S. Yang, J. Tan, Y. Huang, Q. Wang (2014)“An Unconventional Unmanned Autonomous Blimp: Design, Modeling and Simulation". Communications in Comput. \& Inform. Science. Volume 474, pp. 356-367.

[9] M. Battipede, M. Lando, P. Gili (2006) "Mathematical modelling of an innovative unmanned airship for its control law design". Proc.of IFIP. Vol. 202, Syst., Cont., Mod.and Optimization. Eds. Ceragioli. Boston, Springer, pp 31-42.

[10] H. Lamb(1916) "On the motion of solids through a liquid. Hydrodynamics", Dover, New York,4th edition.

[11] L.B.Tuckerman (1926) "Inertia factors of ellipsoids for use in airship design". Report No. 210.NACA.

[12] S. Bouabdallah, R. Siegwart (2005) "Backstepping and Sliding-mode Techniques Applied to an Indoor Micro Quadrotor". Proceedings of the 2005 IEEE International Conference on Robotics and Automation. Barcelona, Spain. 
[13] T. Madani, A. Benallegue (2006)," Control of a quadrotor mini-helicopter via full state backstepping technique", IEEE Conference on Decision and Control, San Diego, CA, USA, pp. 1515-1520.

[14] S. Lee, H. Lee, D. Won, H. Bang (2007)“Backstepping approach of trajectory tracking control for the midaltitude unmanned airship". Proceedings of AIAA Guidance, Navigation, and Control Conference.

[15] E. Hygounenc, P. Soueres (2002)“Automatic airship control involving backstepping techniques”. Systems, Man and Cybernetics, IEEE International Conference on, vol. 6

[16] S.Chaabani, N. Azouz, J. Lerbet, A.Abichou "Modelling of an unconventional airship".11th ASME Biennial Conference ESDA'12, Nantes, France. 1, pp.661-668.

[17] T. Fossen, (1996) "Guidance and control of ocean vehicles" Wiley press.

[18] H.K. Khalil, (1992). "Non linear systems", Michigan State University. 